\title{
UNA ISLA LLAMADA ARBOLEYA (ENRIQUE GÓMEZ ARBOLEYA Y LA PERVIVENCIA JURÍDICA DE UNA METÁFORA)
}

\author{
An island named Arboleya (Enrique Gómez Arboleya and legal prevalence of \\ the metaphor)
}

\author{
Felipe Navarro Martínez \\ Profesor Asociado de Filosofía del Derecho \\ felipenavarro@uma.es \\ Universidad de Málaga
}

Si el tiempo pone al hombre en su sitio, ¿cuál es el mío? Toteking. Tiempo

Para José Calvo González, que siempre iluminará mi vida. Para Pepa Carmona, que me lo prestó.

\section{RESUMEN}

El trabajo pretende volver a traer al primer plano, en el ciento diez aniversario de su nacimiento, el nombre de Enrique Gómez Arboleya, primer Catedrático de Filosofía del Derecho que obtenía dicha condición tras la Guerra Civil, así como después primer Catedrático de Sociología en España y uno de los padres de tal disciplina en España; su trágico final frustró una trayectoria intelectual deslumbrante. Su quehacer había comenzado con un desempeño literario tan notable como prometedor en el núcleo de la vanguardia granadina que encabezaba Federico García Lorca, abandonando sin embargo repentinamente la Literatura para centrarse en el Derecho y en la Filosofía Jurídica -y luego en la Sociología-. Sin embargo algunas metáforas albergadas en su obra literaria perviven en su pensamiento y en su producción científica posterior y permiten un acercamiento de índole narrativa a las razones que le movieron intelectual y vitalmente hasta su suicidio en 1959.

\section{PALABRAS CLAVES}

Enrique Gómez Arboleya, Federico García Lorca, Wilhem Dilthey, Revista Gallo, Filosofía del Derecho, Sociología española, Historia del Derecho.

\begin{abstract}
The paper intends to bring back to the foreground, on the one hundred and ten anniversary of his birth, the name of Enrique Gómez Arboleya, the first Professor of Philosophy of Law who obtained this condition after the Civil War, as well as later the first Professor of Sociology in Spain and one of the parents of such discipline in Spain. His tragic dead frustrated a dazzling intellectual trajectory. His work had begun with a literary performance as remarkable as promising in the nucleus of the Granada avant-garde led by Federico García Lorca. However, suddenly abandoning Literature to focus on Law and Legal Philosophy -and then on Sociology-. Some metaphors harbored in his literary work survive in his thought and in his later scientific production, and allow a narrative approach to the reasons that moved him intellectually and vitally until his suicide in 1959.
\end{abstract}

\section{KEYWORDS}

Enrique Gómez Arboleya, Federico García Lorca, Wilhem Dilthey, Review Gallo, Philosophy of Law, Spanish Sociology, History of Law. 
Sumario: 1. Andén destino Granada. 2. Alba y Noche de gallo. 3. Eugenio Rivas y las islas. 4. En las islas griegas. 5. Islarios. 6. Volver a Ítaca. 7. Conclusiones. Bibliografía.

\section{Andén destino Granada.}

No llegaba desde Boston, sino de Huelva. Vio en un andén, y de seguro que en otros muchos lugares partiendo, que la luz, "brillante y dura, ofrecía su cuerpo a los puñales de los pañuelos que nacerían con la despedida. "Su nombre era Enrique Gómez Arboleya, y había nacido en Castilla el 13 de septiembre de 1910; no en una isla, sino en mitad de una península tendencialmente anfibia y fragmentada. No venía de una isla, aunque acaso lo fue siempre él mismo.

Escribir de Enrique Gómez Arboleya en el año del ciento diez aniversario del nacimiento de uno de los intelectuales más fecundos e inspiradores del siglo XX -y de seguro igual de enigmático ahora que a la fecha de su trágica muerte-, se plantea como una empresa que quizás sólo puede acometerse desde una idea previa: hacerlo como si nada acerca de él hubiese sido escrito, pero sin olvidar que sí. Arboleya, que para quienes lo trataron había dejado el Gómez del padre arrinconado, quizás por pura mayor eufonía del apellido materno, quizás por tratar de zafarse de algún sino albergado en ese primer apellido, había nacido en Cebreros (Ávila), pero fue granadino de paisaje. Los destinos como funcionario de su padre parecieron determinar los viajes de la familia, y así que Arboleya cursase su primera enseñanza en la ciudad de Huelva, una ciudad marítima, abismada al océano sobre un cosido de islas, un océano que lo mismo la acrecenta que la muerde. Así consta en su expediente académico ${ }^{2}$. Va a residir la familia en Huelva cuanto menos entre 1920 a 1924, y él a cursar estudios en el Instituto General y Técnico de Huelva La Rábida, perteneciente entonces al distrito universitario de Sevilla; un centro que va a contar entre sus profesores con Federico de Castro, y entre sus alumnos ilustres pueden tenderse diversos puentes intelectuales. Pues además del propio Arboleya, la lista de esos alumnos de distintas épocas se agiganta con Juan Ramón Jiménez, con el torero Ignacio Sánchez Mejías (que volvió al Instituto y el estudio tras abandonar los toros), Ernesto Feria Jaldón, u Odón Betanzos, o más cercanos a nuestros días, el físico Juan Pérez Mercader o el poeta Juan Cobos Wilkins. Dicho instituto, creado por R.O. de 13 de junio de 1856, será el primer centro de España en el cual, el año 1871, una mujer, Antonia Arrobas y Pérez, se matricule en estudios de Segunda Enseñanza.

Tras los años atlánticos de Huelva pasa la familia a Granada, con el padre desempeñando como magistrado de la Audiencia Territorial. Afirmaba Max Aub que uno es de donde hace el bachillerato; para Arboleya eso significó, entonces, ser para siempre granadino. Cuenta de él su amigo Manuel López Banús ${ }^{3}$ que ya en Granada Arboleya llegó a encabezar la Federación Universitaria Escolar, activada la conciencia política en los estudiantes españoles, llegando ambos a pasar unos cuantos días en la cárcel como consecuencia de sus protestas, a finales de la dictadura primorriverista. Cuando Arboleya ha llegado en esos años a la ribera del Darro, ha encontrado una Granada en ebullición vanguardista en mitad del ambiente tradicionalmente conservador y cerrado de la ciudad

\footnotetext{
${ }^{1}$ Gómez Arboleya, E. Cuaderno de Eugenio Rivas, en gallo. Revista de Granada, 1928, nº 2, pág. 14. Cito por la edición facsímil, 1988, Ed. Comares, Granada.

${ }^{2}$ Expediente personal de Enrique Gómez Arboleya, en http://hdl.handle.net/10272/3821. Según consta en el mismo, su domicilio en Huelva estuvo primero en la calle Castelar, 4, y luego en calle Rábida, 10.

${ }^{3}$ López Banús, M. (1988), El solitario de su inteligencia; en Homenaje a Enrique Gómez Arboleya, Iglesias de Ussel, J. (coord..), 1988, Ayuntamiento y Universidad de Granada, págs.154-160.
} 
de la Alhambra y el Palacio de Carlos V; esa vanguardia granadina es entonces, y acaso también ahora, una insula in flumine nata sin que se tenga claro a quien corresponderá el beneficio de su accesión. A Granada, a los lugares granadinos en los cuales esa vanguardia se abre paso a veces con cierto escándalo, llega Enriquito en pantalón corto, tal y como lo describe Lorca en su entusiasta presentación pública impresa:

“Este es el niño. Resulta increíble sin haber sido jamás precoz. Entró en las letras con el pantalón corto. Ahora ya es casi un hombrecito. Antes de pasar la escarlatina era débil, informal, como un pájaro sin amor. Después de la escarlatina es más sereno, más sentadito, pero su magnífica imaginación emprende raids de mayores riesgos. Perdió lo que tenía de flor, para ganar en fruto jugoso, aunque razonablemente no sea todavía de su propia y única cosecha.

Es pálido. Parece que está iluminado por la luna. Y es un castigador. En los cines y en los teatros, castiga a las niñas con su gesto originalísimo entre tímido y desafiador de las miradas. Su sensibilidad tiene un temblor de infancia y nuevo día, de lo más sugestivo que puede hallarse ${ }^{4}$."

Lorca dirá de él en esa misma semblanza, en esa suerte de alternativa literaria, que se trataba de un literato auténtico, lleno de brillo, sensibilidad, y vocación, y en el cual estaban puestas todas las alegrías y esperanzas. Son esas palabras de 1928; ese año Arboleya no se ha convertido en jurista, aun cuando ya está en la Universidad; aún menos en sociólogo. Ese año de Universidad, Arboleya, a decir de sus condiscípulos es el mejor alumno que ha pasado por la cátedra de Fernando de los Ríos, con quien asiste a la tertulia en el Ateneo junto a Lorca, a Falla, a Ramiro Rico, a Manuel de la Higuera, quien narra que Enrique Arboleya deslumbraba como alumno hablando de Spengler en las clases de Historia del Derecho.

Ese mismo año de Facultad el hermano mayor de Enrique, su único hermano, ante cuya mayor inteligencia Enrique se sobrecogía, se suicida.

\section{Alba y Noche de gallo.}

Antes de alcanzar el final de la década hay que recorrer sus principios. A finales de los años 20 del pasado siglo, y produciendo una consciente hipérbole, no hay poeta español y de habla hispana que no tenga una revista. Los miembros de la Generación del 27 y otros contemporáneos se han lanzado a una carrera cuasi futurista de componer efimeros artefactos en forma de revista literaria. En el mismo espacio van a convivir un clásico como Revista de Occidente con otras que lo serán, como Litoral (Málaga), así como algunas de fulgor efímero, Carmen (Gijón), Verso y Prosa (Murcia) o gallo (Granada), con los nombres de Gerardo Diego, de Jorge Guillén, de Federico García Lorca, incluso de César Vallejo y Larrea (Favorables París Poema), detrás de cada empeño. La Edad de Plata de la literatura española presta ese mismo brillo argénteo a las revistas literarias, como cauce difusor de sus empeños creativos y aun pedagógicos y cuasi revolucionarios.

En Granada, la tertulia de El Rinconcillo del café Alameda es uno de los centros de la cultura granadina entre los años 1915 y 1929. A esta tertulia asisten Federico García Lorca y su hermano Francisco. Hasta la publicación de Impresiones y Paisajes en 1918, Federico no pasa en ella por escritor, sino por músico. Entre muchos notables, a esta tertulia asisten el catedrático y político Fernando de los Ríos, el también catedrático de

\footnotetext{
${ }^{4}$ García Lorca, F. (1928), Alternativa de Manuel López Banús y Enrique Gómez Arboleya; en gallo. Revista de Granada, cit., pág. 22.
} 
enseñanza media Joaquín Amigo -de notable influencia en la conformación de la personalidad de Enrique Arboleya-, los pintores Manuel Ángeles Ortiz -discípulo de Picasso- e Ismael de la Serna, el académico de la Lengua Melchor Fernández Almagro, el músico Manuel de Falla -del cual Enrique Gómez Arboleya acabará siendo durante un tiempo secretario-, Antonio Gallego Burín, quien sería alcalde de la ciudad tras la Guerra Civil, o el periodista y escritor José Mora Guarnido. Tertulia además a la cual en visitas a Granada van a asistir figuras extranjeras como Arthur Rubinstein, Rudyard Kipling o H.G. Wells. Esa tertulia es uno de los lugares en los cuales, hacia 1926, debate Lorca la puesta en marcha de su proyecto de revista literaria: gallo. Revista de Granada. Lorca la llamará así, en minúscula.

Antes del comienzo de ese empeño, una noche de 1924, recuerda Luis Jiménez Pérez en Un hombre ${ }^{5}$-su semblanza de Arboleya para el libro Homenaje, coordinado por Julio Iglesias de Ussel- se produce la inauguración del Ateneo de Granada. En esa reunión, en la calle Varela, está Enrique Gómez Arboleya. Arboleya, Enriquito, como le recuerda Jiménez, va en pantalón corto, atlético, un tanto distante, con porte de efebo. Traban amistad, unidos por el cordaje trenzado por Joaquín Amigo y Lorca; en el grupo que charla animadamente están también Manuel López Banús, José Murciano, Joaquín Amigo. Arboleya tiene aplomo, es atractivo e intimidante, cuenta Jiménez; conoce los clásicos con soltura pese a ser un adolescente. Pronto Amigo y Lorca lo tutelan, el primero hacia la filosofía, el segundo hacia la literatura; al poco el joven Enrique está escribiendo piezas para El Defensor de Granada, dirigido por Ruiz Carnero.

Alrededor de Lorca, o de Amigo y Lorca a decir de los coetáneos de ambos, se irá conformando un núcleo de jóvenes creadores granadinos, que será luego la columna de la revista gallo. La historia de gallo. Revista de Granada es una historia breve, de sólo dos números, febrero y abril de 1928, en mitad de los cuales se publica también Pavo, una suerte de remedo satírico de la propia gallo y obra también de Federico, dando burlona vuelta de tuerca al empeño vanguardista y renovador que anima a estos creadores granadinos. El tercero de los números quedó con los materiales en preparación, abandonado el interés de Federico en ella; sin ese interés la revista ya no pudo continuar. Pues como decíamos había sido la revista idea de Federico que alrededor de 1926 comienza a poner en marcha: el empeño de aglutinar a la resplandeciente vanguardia granadina y lanzarla al mundo, trayendo además a Granada a algunos de sus pares de fuera de ella, de Dalí a Guillermo de Torre. El propósito es una publicación antilocalista, antiprovinciana, una revista de Granada para fuera de Granada, en carta de Lorca.

En esos dos números de gallo y de seguro lo habría hecho en continuidad en el tercero de haber éste aparecido finalmente, publicó los que sepamos sus únicos textos estrictamente literarios Enrique Gómez Arboleya. Federico confiaba sin dudas de ninguna clase en el porvenir literario de su amigo Enrique, a quien dedica, junto a Manuel López Banús, el texto de bienvenida y alternativa en el primer número, ya citado en parte.

El comienzo de la revista iba a estar vinculado con El Defensor de Granada, como suplemento literario del mismo -El gallo del Defensor fue uno de los títulos pensados en origen-. En 1927, relata Antonio Gallego Morell en Ilusión y kikiriki de gallo ${ }^{6}$, Lorca escribe a Melchor Fernández Almagro para contarle que el proyecto está en marcha y pedir su colaboración; ya cuentan, dice en la carta, con Dalí, Jarnés, Falla y Guillén. En la nómina del primer número de gallo, febrero de 1928, aparecerán finalmente las firmas

\footnotetext{
5 Jiménez Pérez, L., El hombre; en Homenaje a Enrique Gómez Arboleya, cit. págs.130-146.

${ }^{6}$ Gallego Morel, A., Ilusión y kikiriki de gallo, en gallo. Revista de Granada, cit., p. VIII.
} 
de Federico García Lorca, Jorge Guillén, Melchor Fernández Almagro, José Bergamín, Dalí, Manuel López Banús y Enrique Gómez Arboleya.

La llegada de la revista tuvo sendos reflejos en forma de actos públicos, con cierta pretensión provocadora, dentro de ese espíritu de vanguardia que a todos animaba. En el primero de ellos, en la Venta Eritaña, el primero en intervenir, en nombre de la redacción de la revista, es Enrique Gómez Arboleya, que junto a Banús y Cirre habían actuado además de correctores; tras él una larga serie de discursos, de entre los que destacan los de los hermanos García Lorca, Federico y Francisco, según la crónica entusiasta del acto que publica El Defensor de Granada el 9 de marzo de 1928.

El segundo de esos actos fue la "Noche de gallo", que se organizará un tanto al modo de los actos que Federico conocía de la Residencia de Estudiantes. Se expuso allí todo el andamiaje que sostenía el empeño de gallo, y se celebra digamos que muerto o casi muerto el gallo al poco de nacer, dado que Lorca se estaba ocupando ya más de la obra propia que de la revista, para cuyo tercer número se acumulaba material de Sebastiá Gasch, Gerardo Diego, Dalí, José María de Cossío -con un trabajo sobre los Machado y los toros-, y el propio Federico. La reunión se celebró el 27 de octubre de 1928, en la Venta de la Lata, impulsada por el Ateneo. Intervendrían en ella Fernando de los Ríos, Joaquín Amigo, Manuel López Banús, Carlos Fernández Casado, Enrique Gómez Arboleya, Francisco Menoyo y Federico García Lorca, quien leyó su Sketch de la nueva pintura usando como acompañamiento de su intervención una proyección de diapositivas.

La intervención de Arboleya en la "Noche de gallo" se titularía Modos de ausencia. Manuel de la Higuera la recuerda ${ }^{7}$ casi como si de un manifiesto futurista se tratara, exaltando la velocidad, la línea recta, el cubo, lo atlético y la práctica al aire libre, la asepsia en la conducta y la presencia. "Gustó mucho lo que dijo y cómo lo dijo" narra Higuera.

Aún se celebraría un tercer acto, mas en puridad no vinculado a gallo sino a Pavo, su remedo burlesco. El nombre del mismo, la "Velada Brumario". De nuevo, como en la anterior, abría el acto Fernando de los Ríos, y lo cerró Julia Rodríguez Danilewski, con una reflexión acerca del papel de la mujer en esa nueva estética de la vanguardia. Las dos aves, gallo y Pavo, habían agitado como un sonajero Granada.

\section{Eugenio Rivas y las islas.}

La obra de Arboleya en la revista gallo, por ende toda la obra literaria de Arboleya publicada, se trata de sendos poemas en el número 2, Amanecer y Flechas con vista al blanco, así como de dos entregas, una en cada uno de los números, de una narración de carácter iniciático que ignoramos si siquiera privadamente concluyó, y que lleva por título Cuaderno de Eugenio Rivas. Serán estas dos entregas, en esa obra inconclusa, ejes sobre los que pivotaré este trabajo. Estas prosas de Cuaderno de Eugenio Rivas justifican más que de sobra la admiración y esperanzas de sus coetáneos, comenzando por Lorca, y hasta su enfado, entendemos que acaso unido a algunos otros motivos de índole más personal, por el abandono de tal vocación literaria, en beneficio entonces del Derecho, del cultivo de la Filosofía, del más puro pensamiento.

La voz narradora del Cuaderno de Eugenio Rivas es la de un adolescente que ofrece de continuo imágenes deslumbrantes y metáforas insólitas que no se agotan en su brillantez sino que están al servicio, de un modo natural y difícilmente sencillo, de una

\footnotetext{
${ }^{7}$ De la Higuera Rojas, M., (1988), Tiempo de juventud; en Homenaje a Enrique Gómez Arboleya, cit., págs. 95-110.
} 
fluidísima y cautivadora peripecia sin asunto declarado. Arboleya es en ese momento un vanguardista de 18 años; a tenor de su trayectoria posterior, incluso dentro de los más encorsetados espacios académicos, yo diría que siguió siéndolo, manteniendo ese espíritu de búsqueda e hibridación de la vanguardia granadina, de alguna manera, hasta su muerte.

Eugenio Rivas está en un internado internacional, en la primera de esas entregas. Su padre es un ingeniero que trabaja en Boston. Ha pensado para él que para estudiar Derecho regresará a España. En esa primera entrega Rivas se revela como un adolescente atrapado por la melancolía, "esa melancolía horrible que hace de los hombres inventores de máquinas de vapor o suicidas", que siente pasear a veces "en un mundo antipáticamente redondo, rodeado de meridianos por todas partes para que no se escapen las gaviotas". Melancolía e islas: la alusiones a las islas aparecen en un par de ocasiones para reforzar esa idea de aislamiento, de ser una isla en el espacio a veces difuso en el cual se mueve el personaje Eugenio Rivas. Y así, describiendo el modo en el cual comparte el espacio escolar con sus compañeros explica como "cada uno se encierra en su melancolía como en islas distintas aunque cercanas, desde donde en los días de calma, pudiéramos hablar por señales". Y más adelante, al regreso de una excursión con muchachas de flor en el pecho y condiscípulos encorbatados, siente de nuevo esa melancolía, solo en mitad del grupo y dice: "Llevo doblada, como un pañuelo, sobre el pecho, toda la angustia de las islas pequeñas, deshabitadas en medio de un océano gris."

En la segunda entrega del Cuaderno, Rivas realiza una breve meditación sobre el viaje8; el personaje está partiendo de viaje y está llegando. Y habla de Boston, de la ciudad que dejó atrás, una ciudad que es mitad tierra mitad mar, de la que recuerda "las cincuenta islas de su puerto", y en la cual, a "la orilla del Charles-Rive9, las muchachas de la Universidad, sin saber que eran bellas, estudiaban griego". Narra en esta segunda entrega el deseo de su padre de que para estudiar Derecho regrese a su patria, a España, a Granada. Y para cerrarla se lanza a un autorretrato, en el cual, enfrentado a las imágenes especulares de quienes lo trataron hasta su muerte, es muy complejo y hasta inconveniente evitar la tentación de ver en ello ese cierto strip-tease inverso, en palabras de Vargas Llosa10, vertebrador de toda novela y diría que de todo texto literario.

\footnotetext{
${ }^{8}$ Elijo esa expresión para hacerla coincidir con un título del propio Arboleya. En 1952 va a publicar un texto con el título de Breve meditación sobre el viaje, en el $\mathrm{n}^{\circ} 35$ de la revista Cuadernos Hispanoamericanos, págs. 41-54.

${ }^{9}$ Transcribo del original. Se trata sin duda de una errata, y referirse al Charles River. En febrero de 1954 otro poeta vinculado inicialmente a la Generación del 27 aun cuando su obra pertenece según su propio criterio a la generación de la posguerra, Dámaso Alonso, datará un poema escrito junto a ese río, del que toma el título, compartiendo el paisaje que Arboleya introduce en su texto. El título del poema es $A$ un río le llaman Carlos (Charles River, Cambridge, Massachusetts), y comienza así: "Yo me senté en la orillal quería preguntarte, preguntarme tu secreto;/convencerme de que los rios resbalan hacia un anhelo y viven; / y que cada uno nace y muere distinto (lo mismo que a ti te llaman Carlos)". Un artículo de profesora Mercedes Junquera toma el título de ese poema escrito en diálogo con el Charles River arboleyano como eje: Junquera, M. (1984). A un río le llamaban Dámaso. Hispania, 67(2), 193-200. doi:10.2307/341722. Posteriormente lo usará también Francisco Umbral para una columna sobre el autor de Hijos de la ira en El Cultural- https://elcultural.com/A-un-rio-le-llamaban-Damaso -. Y finalmente dará también título a una antología de su obra publicada en 2002; A un río le llamaban Dámaso: antología poética, Vitruvio, Madrid, 2002. Como se ve, el Charles River cuenta con una presencia nada accidental en la creación literaria española del siglo XX.

10 "Escribir una novela es una ceremonia parecida al strip-tease. Como la muchacha que, bajo impúdicos reflectores, se libera de sus ropas y muestra, uno a uno, sus encantos secretos, el novelista desnuda también su intimidad en público a través de sus novelas. Pero, claro, hay diferencias. Lo que el novelista exhibe de sí mismo no son sus encantos secretos, como la desenvuelta muchacha, sino demonios que lo atormentan y obsesionan, la parte más fea de sí mismo: sus nostalgias, sus culpas, sus rencores. Otra diferencia es que
} 
En ese autorretrato de Eugenio Rivas, escribe Arboleya: "Tengo cualidades que envidiar a cada uno de mis compañeros, pero yo procuro desconocerlas. Tengo también defectos, pero los ignoro y no me preocupan. Como creo a la gente inferior, la trato cariñosamente pero no la amo. Para todos tengo un gesto acogedor y distanciado, heredado de no sé qué rey. Sería seguramente cruel si no fuera melancólico... Soy inteligente pero me falta esa voluntad que levanta los puentes sobre los ríos y hace los hombres genios o grandes oradores. Abandono fácilmente el trabajo, cerrando los libros ... todos los días lucho conmigo mismo y me engaño ... en estos ratos de melancolía censuró agriamente mi pereza, desnuda de silogismo. Además, no es esto todo. Desprecio a la gente por sus defectos, sin notar que iguales los tengo yo. En los demás los veo mayores, pero son los mismos ... En clase puedo decir sin parar, sin vacilación ni duda, los sistemas de los grandes filósofos que han pensado acerca de la inteligencia, del corazón del hombre; en todos me encuentro.... me emociono fácilmente con las poesías de Juan Ramón, me sé de memoria casi todos los poemas de Valery ... Verdad es que me hago perfectamente el nudo de la corbata, que sé andar a ese paso maravilloso que revela una perfecta musculatura en las piernas..." Si uno enfrenta esa descripción temprana a las narraciones acerca de quién fue Arboleya las imágenes parecen ser bastante especulares.

Tras de eso, nada. Arboleya abandona la literatura. Hará después columnismo con mayor o menor frecuencia y a veces con sentido alimenticio, pero deja la literatura. Recorramos brevemente el sabido itinerario profesional de Arboleya desde ese momento11. En la Facultad granadina va a completar los estudios de Licenciatura, obteniendo al segundo año de los mismos el premio de la Fundación Ovelar del Arco, así como el premio extraordinario a la finalización de la misma, el mes de septiembre de 1931. Durante el curso 1932-1933 se le va a encomendar la docencia en la cátedra de Derecho Natural y Filosofía del Derecho, cuyo programa va a impartir hasta el 30 de junio de 1935, amparado por la figura de una auxiliaría interina. Su situación administrativa varía tras superar el 4 de marzo de 1933 la correspondiente oposición, tras la cual pasa ocuparse también de las explicaciones de Derecho Romano e Historia del Derecho Español. Habrá cubierto sus cursos de doctorado en Madrid, durante el periodo 19331934, superando en ellos las asignaturas de Estudios Superiores de Derecho Penal y Antropología Criminal, Derecho Municipal Comparado, Historia de las Instituciones Políticas y Civiles de América, y Filosofía del Derecho. A mediados de, año 1934 Enrique

en un strip-tease la muchacha está al principio vestida y al final desnuda. La trayectoria es la inversa en el caso de la novela: al comienzo el novelista está desnudo y al final vestido. Las experiencias personales (vividas, soñadas, oídas, leídas) que fueron el estímulo primero para escribir la historia quedan tan maliciosamente disfrazadas durante el proceso de la creación que, cuando la novela está terminada, nadie, a menudo ni el propio novelista, puede escuchar con facilidad ese corazón autobiográfico que late fatalmente en toda ficción. Escribir una novela es un strip-tease invertido y todos los novelistas son discretos exhibicionistas." Vargas Llosa, M. (1971), Historia secreta de una novela, Tusquets, Barcelona, págs. 7-8.

${ }^{11}$ Para un más exhaustivo acercamiento a la biografía personal e intelectual de Enrique Gómez Arboleya, que excedería los límites de este trabajo y lo fatigarían en exceso, además del contenido del citado volumen Homenaje a Enrique Gómez Arboleya resultan insustituibles los trabajos de los profesores Rodríguez Ibañez, Mesas de Román y Peláez Albendea, a quienes agradezco su generosa ayuda a la hora de tratar de responder a algunos enigmas que como islas desconocidas aun perviven sin descubrir respecto de Arboleya. En especial deben citarse: Gómez Arboleya, E. (2008) Obra Póstuma, Edición de José Enrique Rodríguez Ibañez, Estudio Introductorio de Pedro José Mesas de Román, CIS, Madrid; Peláez, M.J. (1995), Infrahistorias e Intrahistorias del Derecho Español del siglo $X X, 2^{\mathrm{a}}$ edición revisada y aumentada, ,Cátedra de Historia del Derecho y de las Instituciones, Universidad de Málaga. 
Gómez Arboleya va a recibir una beca de la Universidad de Granada que le va a permitir ampliar sus estudios en la Universidad de Berlín bajo la dirección de sus profesores de Filosofía, Eduard Spranger y Nicolai Hartmann.

El 31 de mayo de 1935 obtiene el grado de doctor tras la presentación de su tesis sobre Herman Heller, la cual no verá la luz hasta 1940. En ese año se convoca la oposición por el turno libre de la Cátedra de Derecho Natural y Filosofía del Derecho de la Universidad de Sevilla. Enrique Gómez Arboleya obtendrá entonces dicha plaza y tomará posesión de ella con fecha 14 de noviembre de 1941. La presencia de Enrique Gómez Arboleya en Sevilla será breve, reducida a un solo año académico, ya que el 4 de noviembre de 1941 va a solicitar su traslado a Granada, el cual le es concedido el 7 de diciembre; va a cesar el día 31 en el claustro de la Hispalense y tomará posesión de su destino en Granada el 2 de enero de 1942. En Granada permanecerá hasta su marcha a Madrid, que será progresiva, y su acceso a la cátedra de Sociología en 1954. Aun así, volvió siempre que pudo a su particular Ítaca, Granada.

No se alejó Arboleya de la cultura ni de cierta vida social en torno a ella, pero sí del cultivo de la literatura y de esos círculos de vanguardia, desde 1928. Como Bartleby, prefiere no hacerlo más, y se aparta. ¿Las razones? Quizás que las leyes de la creación le parecían menos interesantes que las propias de la Ciencia del Derecho y la Legislación; o que se encontraba más a gusto diseccionando sistemas filosóficos -esos que Eugenio Rivas dice conocer y compartir como propios- que construyendo imágenes y trenzando párrafos; o que la presión de Lorca, una presión con pretensión afectiva más allá de la pura amistad, produjo un frontal rechazo en alguien como Arboleya, quien, como describe a su personaje Rivas, parecerá en lo sucesivo a quienes lo conozcan afectivo pero siempre distante, siempre poseedor de un secreto doloroso: relatos alternativos, en suma, no descartables, para alcanzar un mismo resultado.

\section{En las islas griegas.}

Sus alumnos en la Universidad de Granada recuerdan que el profesor Arboleya comenzaba su docencia de Derecho Natural hablando de los griegos y de Grecia: "Grecia era una isla de luz en medio de un océano de tinieblas y el heleno podía llamar a los otros pueblos "bárbaros". ${ }^{12 " ~ E s o s ~ g r i e g o s ~ c u y o ~ i d i o m a ~ e s t u d i a b a n ~ l a s ~ m u c h a c h a s ~ a ~ l a ~ o r i l l a ~ d e l ~}$ Charles-Rive en la narración de Arboleya de 1928 aparecían ahora en sus clases de 1946, tras una guerra civil y la obtención de la Cátedra en 1940 de por medio. Arboleya, como esas muchachas que no sabían que eran bellas, aprendió griego él mismo para mejor adentrarse en el estudio de la metafísica.

En 1952 Arboleya publica La polis y el saber social de los helenos ${ }^{13}$. El artículo se dirige a analizar la posible existencia de una sociología o pre-sociología en la Hélade en los primeros años de conformación de la democracia ateniense. Y comienza describiendo de este modo, antes de hablar de Temístocles, la especial geografía griega, citando parcialmente a Glotz: "Cuando venimos de Asia, el primer territorio que nos -sale al encuentro es un país diseminado por el mar, y allí donde puede llamarse tierra firme dividido en muchas pequeñas porciones. Las islas forman el archipiélago; la tierra firme es una península de estrechas lenguas de tierra salpicadas de ensenadas. En Grecia todo es distinto... en estas riberas desmenuzadas, en el fondo de estas bahías, en estas islas, van a desparramarse ciudades minúsculas, que estarían abocadas al aislamiento y a la

\footnotetext{
${ }^{12}$ Roca Roca, E. (1998), Desde la esencia del existir jurídico; en Homenaje..., cit., págs. 205-218.

${ }^{13}$ Gómez Arboleya, E. (1952), La polis y el saber social de los helenos, Revista de Estudios Políticos, $\mathrm{n}^{\circ}$ 65 , págs. $49-83$.
} 
reclusión si no tuvieran una larga mirada al exterior por la fachada marítima. La tierra fragmentará aquí un pueblo cuya patria común será el mar."

1928, 1946, 1952: las metáforas que incluyen islas como parte de los términos comparativos son frecuentes y recurrentes en Arboleya, tanto en sus textos literarios como en los científicos, que aúnan la calidad investigadora con la literaria. La experiencia de la isla es una experiencia directa de los años onubenses de Arboleya, años sobre una tierra de barras, marisma, islotes, meandros de dos ríos que se confunden entre sí y con el mar. Un paisaje tan primigenio como esa Grecia en la cual conviven dioses y hombres, historia y mito, en la cual la festuca la empuñan poetas, reyes y adivinos, vara que señala, marca y mide. En la Grecia de Aquiles y en la Andalucía de Arboleya los terrenos de la polis se confunden con el campo arado y señalado con la vara del campesino, que traza en él huertos o campos de pasto, islotes de vida ordenada. En su artículo de 1952, abandonada la literatura pero no la voluntad de estilo, Arboleya recurre a enfrentar historia y mito, desmenuzando éste aun cuando el mito sea más bello que la historia, y ésta más complicada que aquel. La polis es un logro, significa que el Derecho se abre paso, pero también un signo de imposibilidad, la de construir una historia del individuo independiente de la del Estado. La idea de pontos es común a todo islario, a todo archipiélago; tender puentes entre riberas y orillas, habilitar y construir los pasos, y esa es un tarea que incumbe también al Derecho, es una de sus poéticas, construir una sociedad cosida en un espacio geográfico y por ello también social que propende al aislamiento. La tensión geográfica, la tensión social, la tensión histórica, propician el aislamiento. Y el saber griego, el saber de los helenos un saber construido sobre un escenario de islas, muestra que es posible, tanto en la historia como en el mito, que los dioses con la razón venzan a los titanes que confunden violencia con aquella.

Pero es, claro, 1952. A ese año lo van a suceder los correlativos hasta el suicidio de Arboleya en 1959. España es desde hace años no una península sino una isla, un país aislado en el cual la violencia se ha disfrazado de Derecho, y eso es lo que contempla Arboleya desde 1936; desde que siendo secretario de Falla acude junto a él a interceder por Lorca el mismo día en el cual su antiguo amigo y valedor literario es fusilado; luego intercederá por el rector Vila, por Gerda Leimdörfer, su mujer, de quien logra la liberación, así como por una amiga de Gerda, Gretel Adler, de quien se decía que la pretendía Arboleya, y que será finalmente asesinada por falangistas.

La filiación de Arboleya en un determinado falangismo en cierto modo heredero de las ideas futuristas y vanguardistas, lo protegerá durante la guerra pero lo aislará como al resto de intelectuales con esa militancia. Recordemos que su lección de acceso a la Cátedra en 1940 se publicará en la revista Escorial, cuyo ideario rector según manifestaba su primer editorial era "Contribuir al restablecimiento de la comunidad intelectual, invitando a cuantas firmas de pensadores investigadores poetas y eruditos quisieran, sin necesidad de prestarse a apología líricas del régimen, pero también sin pretensiones de propaganda política, sumarse con su gesto de aproximación a un verdadero y auténtico servicio a la ciencia española." De nuevo estamos ante la isla, ahora como metáfora de exilio interior, para quien se había formado en la Universidad republicana, una universidad en la cual no era necesario exhibir méritos de combate como méritos académicos, como se pretendió hacer valer respecto de otros aspirantes durante los ejercicios de acceso a la cátedra obtenida de modo abrumador por Arboleya en 1940. 


\section{Islarios.}

Afirma Derrida ${ }^{14}$ que no hay mundo, sólo islas. La isla ha pasado a ser, acaso ha sido siempre, desde la isla de Polifemo, mito y categoría además de accidente geográfico. Podemos cartografiar islas reales, islas imaginarias, islas invisibles, islas metafóricas, y también islas jurídicas, la regulación de las islas en el Derecho, su posesión, su propiedad, sus usos, sus frutos, y también como Derecho; Carnelutti usa la imagen de la isla misteriosa -ecos de Jules Verne ${ }^{15}$ - para hablar de qué parece que sean los hechos en Derecho, Carlos Nino alude a la no insularidad del discurso jurídico ${ }^{16}$. El mito de Robinson, el habitante por antonomasia de la isla, ofrece sus propios mitemas, que tienen que ver con el naufragio, la soledad, con el exilio, con la inevitabilidad del aislamiento, y aun cuando no sea éste el espacio para desarrollar la idea, entiendo que ciertas concomitancias existen entre el héroe de Dworkin, Hércules, y el héroe moderno de Stevenson, Robinson. Las islas se ocupan por el Derecho y desde el Derecho, y aun las más imaginarias son contemplables y analizables y proponibles con un contenido jurídico, y más desde una perspectiva iusfilosófica ${ }^{17}$. La isla es una poética y una propuesta de sentido filosófico y jurídico, así como lo son también dos de sus habitantes por antonomasia, el exiliado y el náufrago.

Respecto del exiliado, el uso de las islas como instrumento vinculado al reproche jurídico esencialmente penal cuenta con una larga historia, desde su regulación romana en la Lex Julia de adulteris coercendis. Nuestro derecho histórico usará las islas de confinamiento como discutida herramienta de represión. Serán otros países, como Inglaterra -el uso de Australia es paradigmático-, Francia o Estados Unidos -la idea de roca-prisión o isla-prisión encuentra también un modelo emblemático en la isla de Alcatraz- los que las usen con mayor profusión, aceptación y ausencia de debate. Regresando al caso español y a un autor cuya obra traza secantes con la Filosofía Jurídica debemos citar que en 1924, el mismo año en el cual Arboleya hace su presentación pública en Granada en la inauguración del Ateneo, la dictadura de Primo de Rivera ordena el destierro de Unamuno a Fuerteventura. Durante la guerra civil Arboleya se exilia en Maracena, para protegerse de los avatares bélicos -su preparación académica ese período no es sino otro medio de exilio interior, de aislamiento, de confinamiento-. En general ese refugio al interior no es sino un ejemplo más del uso, constante en esos años en todos los órdenes intelectuales, del aislamiento, de la conversión en islas de los exiliados, aun de los llamados exiliados interiores. En el caso de los profesores de Filosofía del Derecho huidos y refugiados como exiliados en el extranjero parece más obvio el recurso al símil, pero no lo es menos en el caso de los que permanecen en algunos casos orillados, tolerados, vistos con cierta prevención ${ }^{18}$; Arboleya será así visto no sólo por su ausencia de intervención en el combate, sino también por su cercanía e intercesiones por personajes

\footnotetext{
${ }^{14}$ Derrida, J., (1989) La deconstrucción en las fronteras de la filosofía. La retirada de la metáfora. Paidós, Barcelona. Traducción de Patricio Peñalver.

${ }^{15}$ Verne, J. (1874), L'T̂le mystérieuse, publicada por entregas en Magasin d'Education et de Récréation, 1874-1875.

16 Nino, C.S., (1994) Derecho, Moral y Política. Una revisión de la teoría general del Derecho, Ariel, Barcelona, págs. 79-83.

${ }^{17}$ Para un aprovechamiento y una muy sugerente indicación cartográfica de islas e islarios, vid. Calvo González, J., (2005), Sobre Derecho y geografias simbólicas: Notas para una Islandia Jurídica; en Derecho. Revista de la Facultad de Derecho. UNSA (Universidad Nacional de San Agustín). Nueva Era, Año 7, núm. 7, noviembre de 2005) Arequipa (Perú), pp. 429-448).

18 De modo específico vid. Rivaya, B. (2017) El exilio iusfilosófico español (1936-1977/1981), Doxa: Cuadernos de filosofía del derecho, No 40, 2017, págs. 175-202.
} 
como Lorca o Salvador Vila ,pese a su vinculación originariamente más de índole falangista que no de pura cercanía al régimen franquista. Otro caso que entendemos que podrá acogerse a la metáfora sería el de Felipe González Vicén, excluido de su cátedra en Sevilla y que pasó finalmente a la Universidad de La Laguna -de nuevo Canarias-; el profesor González Vicén dedicará precisamente a Unamuno algunos trabajos ${ }^{19}$ en el período en el cual, excluido de la Cátedra de Sevilla, permanece refugiado, exiliado, en Berlín.

Y del exiliado al náufrago de su isla. La regulación histórica de la insula in flumine nata preveía la accesión desde el fundo ribereño. Arboleya fue eso mismo, una isla en mitad del cauce del Darro, surgida de pronto y que unos y otros trataron de aprovechar, sin percibir acaso que él actuaba como isla y como náufrago de sí mismo, pues es el naufrago quien da sentido a la isla deshabitada. Desde entonces, desde su abandono de la literatura en 1928, se condujo así, como el habitante de una isla, como una isla con un solo habitante. Arboleya pasa de ser parte de un grupo, el grupo de gallo, del grupo que desde el fundo ribereño accede a la isla nacida en mitad del cauce, a estar solo, sin el otro, en una isla abandonada, una isla que debido a la Guerra Civil y sus posteriores consecuencias, al borrado de ciertas cartas de navegación intelectuales, ideológicas, políticas, queda lejos de las rutas conocidas; naufraga todo, y pasa a ser, además de ser isla, a ser Robinson, y de algún modo así se conducirá en lo sucesivo, náufrago hecho siempre algo velado, isla cercana aunque distante.

\section{Volver a Ítaca.}

Arboleya semeja Robinson porque el otro no está presente en su obra. Contempla la sociedad desde un punto de vista amplio y transversal, como no se está viendo entonces, se adelanta a la idea de que cualquier comprensión de los fenómenos sociales, políticos, jurídicos, debe necesariamente ser mestiza. Pero dando la razón a sus reflexiones acerca de los helenos, no contempla a los otros.

En Sobre la noción de persona ${ }^{20}$ Gómez Arboleya hace un recorrido por la historia de conformación del concepto, pero el concepto que no sale en ese recorrido es el de el otro. Sólo la afirmación del individuo, pero no que sea parte de esa definición y afirmación la relación con el otro. Arboleya había desempeñado funciones en la Cátedra de Derecho Romano en 1949, pero de sus lecciones no acude ni rescata el concepto de affectio societatis para definir la persona, que en esa reflexión permanece aislada de lo otros y en ningún caso se define en relación al otro, a la existencia del otro. La distancia personal de Arboleya está en esa ausencia de afectividad social real, y por ende en la imposibilidad de contemplar el fenómeno jurídico como una manifestación afectiva relacionada con el deseo de permanecer unidos.

Arboleya, que había abandonado la literatura, la poesía, leyó sin cesar a Wilhem Dilthey, que sostenía que la poesía era una herramienta de interpretación y de comprensión esencial de la realidad. Muchas de las afirmaciones contenidas en la obra de éste pueden servir para orientar la perspectiva desde la cual pretendo contemplar la evolución de aquel. Para Dilthey la vida era una misteriosa trama de azar, destino y carácter, y la vida de Arboleya responde a esa aproximación diltheyana para una

\footnotetext{
${ }^{19}$ González Vicén, F. (1938), Unamuno und das Problem Spaniens. Geist der Zeit, Berlín; y (1943) La figura de Don Quijote y el donquijotismo en el pensamiento de Miguel de Unamuno. Romanische Forschungen, Hamburgo, vol. 57, 2/3.

${ }^{20}$ Gómez Arboleya, E. (1949), Sobre la noción de persona, Revista de Estudios Políticos, nº 47, págs.. 104116, y (1950) Más sobre la noción de persona, Revista de Estudios Políticos, nº 49, págs.. 107-124.
} 
definición tajante del concepto. Narra Manuel Orozco Díaz su encuentro en Granada, su ciudad, con Arboleya poco antes del suicidio de éste ${ }^{21}$. En ese relato surge el nombre de Dilthey y la lectura constante de Arboleya de Vida y Poesía ${ }^{22}$, que su interlocutor acomete en esos días. La obra de la poesía, sostiene Dilthey, supone una sección de la realidad mostrando una cualidad de ésta que nunca se había visto de ese modo. Las leyes que gobiernan la creación, las reglas de la creación y de la crítica, deben ser universalizables. Al analizar la obra de Goethe, de Novalis, de Hölderlin, Dilthey atisba que el poeta al construir la obra hace evidente las conexiones de sentido que ésta tiene con la vida. La poesía, la obra creadora, pone de manifiesto el valor y la conexión de las cosas. Por tanto la obra poética debe proporcionar esas leyes universalizables y herramientas de comprensión y de expresión de sentido.

Se sostiene por sus contemporáneos que Arboleya sustituyó o mejor, optó sin vuelta atrás, por abandonar la emotividad de la creación literaria en favor de la frialdad filosófica, y sin embargo, la obra de Dilthey y su predilección por ella apuntaría a una difícil convivencia personal con esa decisión. En esa charla granadina Orozco refiere esa lectura de Dilthey junto con la tesis de Tierno, una insoportable exigencia de perfección investigadora y docente, unidos a un padecimiento mental previo, como causantes de la crisis aguda que le lleva al suicidio. En la misma conversación ambos debaten acerca de las razones de Ganivet, otro suicida. Y luego se despiden, una despedida que no tendrá remedio.

\section{Conclusiones.}

Resulta imposible conocer el motivo que lleva a alguien a concluir un camino. Existe una imposibilidad de entrada al punto de vista de interno desde el cual se contempla y alcanza la certeza de que un camino vital está concluido. Hablando de un jurista como fue Arboleya la anterior frase podría plantear ciertas resonancias hartianas, pero el lugar desde el cual contemplo esta perspectiva es esencialmente kafkiano: "Solo las partes implicadas pueden juzgar de verdad, pero precisamente su condición de partes implicadas les impide juzgar. Por eso en el mundo no existe la posibilidad de juzgar, sino solo su apariencia. ${ }^{23}$ " Acaso Arboleya, en un mundo lleno de juicio, adquirió esa convicción de imposibilidad, la certeza de que sólo podemos situarnos ante la apariencia. Es decir, ante un constructo, ante narraciones, ante relatos; los que había dejado de escribir.

Se ha apuntado como hemos expuesto, entre las razones de la decisión final de Arboleya, entreverada de sus propios e íntimos padecimientos, una suerte de conciencia sobrevenida de que su capacidad intelectual no era infinita, y no era capaz de alcanzar ya el control de las herramientas que la sociología norteamericana imponía ${ }^{24}$; de nuevo ese relato posee cierta resonancia hartiana y kafkiana, pero no es sino otro relato. Contemplar

\footnotetext{
${ }^{21}$ Orozco Díaz, M.(2016), Figuras en la Granada de Lorca, Dauro, Granada, págs. 165-179.

22 Dilthey, W.(1905), Das Erlebniss und die Dichtung. Vida y Poesía, Fondo de Cultura Económica, México, 1945, Versión de Wenceslao Roces.

${ }^{23}$ Kafka, F. (1917), Cuaderno en octavo G (1917-1918), en Obras Completas, III, Narraciones y otros escritos, Galaxia Gutenberg, Barcelona, 2003, págs. 619-620.

24 “A mi juicio, el encuentro de Gómez Arboleya con la sociología americana, formal, analítica, cuantitativista, que utiliza modelos matemáticos para el análisis social, fue uno de los hechos que precipitaron su muerte. Es asombroso pero es así, un profesor entregado por completo a sus tareas intelectuales, que en un periodo de agotamiento físico y de febril esfuerzo intelectual, al no poder rápidamente aplicar métodos y criterios que le eran extraños y que exigían instrumentos nuevos para su aplicación, cae en una depresión profunda." Tierno Galván, E. (1988), Evocación del profesor Enrique Gómez Arboleya, en Homenaje..., cit., pág. 238.
} 
esa versión desde un punto de vista externo, como la más plausible, la que queda y por tanto es la más cercana a la verdad, entiendo que sólo es producto de que esa aceptación de algún definitivo modo simplifique y calme entiendo que algo superficialmente nuestra incomprensión. Contar es comprender, sostenían Benjamin y Dilthey; la poesía nos abre a la comprensión de la vida. Leía Arboleya Vida y Poesía y hablaba con Orozco por las calles de una Granada en la cual asoma en el cauce del Darro la sombra de un secreto como una moneda de plata en el lecho del río, usando un símil del propio Arboleya en Cuaderno de Eugenio Rivas.

Arboleya venía de una Universidad que crecía paralela a la Institución Libre de Enseñanza. Había militado en la vanguardia, y luego sólo le exigieron militar, sin más, sin razón alguna, sólo obediencia ciega. Abandonó la literatura y las riberas del grupo gallo, y cuando la Guerra segó la obra de la República, quedó solo, sin affectio societatis, a merced de los cambios en la violenta marea política. Su depuración, durante la cual Falla presionó a Pemán todo lo que pudo para que lo fuese sin responsabilidades y regresase a la docencia, la pasó poniendo sellos en una ventanilla tras haber estudiado en Alemania, y haber estudiado griego para poder seguir avanzando en su formación. En sus ejercicios de Cátedra se discutió su ausencia de méritos en combate, ya que había sido declarado inútil para la milicia. Y Arboleya se refugió en la forma, en cierta eficacia, en la apariencia; hombre siempre algo pretenciosamente vestido, que deslumbraba en clase a alumnos y alumnas, que imponía una amable distancia y poseía, a decir de Carmen Castro de Zubiri, cierto engolamiento y soberbia que le hacían desdeñar tareas que consideraba inferiores. Sus alumnos recuerdan no sólo sus corbatas sino sus alardes de conocimiento, lo que hoy sería fácilmente tomado por perfecta transversalidad; entender y explicar el Derecho no como una creación de laboratorio, aséptico, sino contaminado por la Historia y la sociedad en que se desarrolla. En un sistema vigilante y cerrado al exterior, no debió ser tarea sencilla ser Enrique Gómez Arboleya, que estaba llamado a emprender raids de mayores riesgos, según vaticinaba su entonces amigo Lorca. La lectura de Dilthey en mitad de su crecimiento en el estudio sociológico, esa observancia permanente de cómo las raíces de derecho y poesía sostienen el tallo de la vida, hacen pensar que, como dice Orozco Díaz en su semblanza, Arboleya había entrevisto, entiendo que con percepción de fatalidad, las grietas de sus decisiones; para quien había comenzado como un narrador imaginativo y poderoso, las narrativas sociales y jurídicas de su tiempo, tan carentes de color, no le harían albergar grandes esperanzas. Todo ello se traduce en la ausencia del otro en su reflexión jurídica, porque el otro, en el tiempo gris del Arboleya scholar, es casi siempre la amenaza de un juicio. El personaje Eugenio Rivas afirma en su narración: "Ya tendréis tiempo de conocerme mejor"; sin embargo, en lo que respecta a su creador, a Arboleya, no dio él margen ni espacio, ni hubo tiempo.

Arboleya, ya es sabido, el día de la llegada del presidente Eisenhower, una visita que significaba el comienzo de cierta apertura en el franquismo, se pegó un tiro en su casa de Madrid. Llovía sin cesar ese día, según las crónicas. Muchos son los motivos de un hombre, y quizás ninguno sirve ni ninguno es válido si quien los afirma es otro hombre; la mirada del otro no alcanza a ver siempre, solo contamos con el punto de vista interno, sólo con la apariencia del juicio, sólo con la interpretación. Pero contar con el otro, contarnos junto al otro, quizás es lo que Arboleya no supo o no quiso hacer. Quisiera pensar que Enrique Gómez Arboleya, brillo, velocidad, máquina, poesía, deliberó sobre todo ello sin dolor en el momento decisivo, como quien pasa la vida "en una villa por la que cruza un río, con sauces despeinados y amarillos mimbres", usando una descripción gozosa del Cuaderno de Eugenio Rivas. Y que así fue como después partió, con cierto estruendo que sólo oímos más tarde, y que aún resuena. Que fue así cómo Arboleya, 
Enriquito, Enrique Gómez Arboleya, "descendió suavemente por la rampa que une el misterio y la vida, el silencio y la luz, y abandonó el espejo", el espejo de la vida, y que quien siempre había navegado en derrota compuesta lo hizo entonces sin rumbo cierto, a merced del tiempo, como una isla flotante.

\section{Bibliografía.}

- CALVO GONZÁLEZ, J. (2005) "Sobre Derecho y geografías simbólicas: Notas para una Islandia Jurídica", en Derecho. Revista de la Facultad de Derecho. UNSA (Universidad Nacional de San Agustín), Nueva Era, Año 7, núm. 7, Arequipa (Perú).

- DERRIDA, J. (1989) La deconstrucción en las fronteras de la filosofía. La retirada de la metáfora. Paidós, Barcelona. Traducción de Patricio Peñalver.

- DILTHEY, W. (1905) Vida y Poesía, Fondo de Cultura Económica, México, 1945, Versión de Wenceslao Roces.

- GÓMEZ ARBOLEYA, E. :

- (1928) Cuaderno de Eugenio Rivas. gallo. Revista de Granada, 1928, núms. 1 y 2, Edición facsímil, 1988, Ed. Comares, Granada.

- (1949) “Sobre la noción de persona”, Revista de Estudios Políticos, núm. 47.

- (1950) "Más sobre la noción de persona”, Revista de Estudios Políticos, núm. 49.

- (1952) "La polis y el saber social de los helenos", Revista de Estudios Políticos, núm. 65.

- (2008) Obra Póstuma, Edición de José Enrique Rodríguez Ibáñez, Estudio Introductorio de Pedro José Mesas de Román, CIS.

- OROZCO DÍAZ, M. (2016) Figuras en la Granada de Lorca, Dauro, Granada.

- PELÁEZ, M.J. (1995) Infrahistorias e Intrahistorias del Derecho Español del siglo $X X, 2^{\mathrm{a}}$ edición revisada y aumentada, Cátedra de Historia del Derecho y de las Instituciones, Universidad de Málaga.

- RIVAYA, B. (2017) "El exilio iusfilosófico español (1936-1977/1981)”, Doxa: Cuadernos de Filosofia del Derecho, núm. 40.

- VV.AA (1988) Homenaje a Enrique Gómez Arboleya. Iglesias de Ussel, J. (coord.), Ayuntamiento y Universidad de Granada. 